\title{
EMISSION REDUCTION BY HYDRAULIC HYBRIDS
}

\author{
Seppo Tikkanen ${ }^{1 *}$, Mikko Heikkilä ${ }^{2}$ Matti Linjama ${ }^{3}$, Kalevi Huhtala ${ }^{3}$ \\ ${ }^{1}$ DIMECC Ltd, Korkeakoulunkatu 7, 33720 Tampere, Finland \\ ${ }^{2}$ Agco Power Ltd, Nokia, Finland \\ 3, Tampere University, Automation Technology and Mechanical Engineering, Korkeakoulunkatu 6, 33720 \\ Tampere, Finland \\ * Corresponding author: Tel.: +358 40 8402780, E-mail address: seppo.tikkanen@dimecc.com
}

\begin{abstract}
Emissions of non-road machines are reduced by precise control of combustion process inside the engine and by after-treatment systems. One additional measure is the hybridization of the powertrain, which can be used to stabilize the engine load. This reduces harmful emissions because most nitrogen oxide emissions and particle emissions are related to sudden load and speed changes of the engine. In this study, four different hydraulic hybrid systems and their emission reduction potential are tested in one case study of a forwarder. The comparison study was done using a hardware-in-the-loop system (HIL) that consisted of a real-time simulation model, hydraulic secondary controlled loading system, real diesel engine, and emission measurement systems. The most efficient system (i.e., the system with the lowest fuel consumption) was the Four-pressure system. However, the difference between this system and the second-best system was negligible, and fuel consumption was about $40 \%$ less than with the reference system (a load-sensing system). Results showed that absolute emissions can be reduced by hybridization. Nitrogen oxide emissions were $15-25 \%$ lower and particulate matter emissions were 60-75\% lower. The Four-pressure system had the lowest emissions. All studied hybrid systems resulted in reduction in fuel consumption and harmful emissions in the studied use case.
\end{abstract}

Keywords: Hydraulic hybrid, emissions

\section{INTRODUCTION}

The efficiency of mobile machines has been studied widely during the last decade. A lot of effort has been put into reducing fuel consumption and carbon dioxide emissions. At the same time, the exhaust emission regulations of engines in Europe, the USA, and Japan have become more and more strict, leading to reduced emissions from new mobile machines. The regulations limit emission of hydrocarbons $(\mathrm{HC})$, carbon monoxide (CO), nitrogen monoxide (NOx) and particle matter (PM) per produced kilowatt-hour $(\mathrm{kWh})$. However, these regulations only limit the emissions of the engines, not the emissions of the machines directly. The validation tests are made for the engine in laboratory conditions with predefined load cycles. The loading cycle of the emission tests are composed of various measured real cycles, but they are nonetheless laboratory tests without the variation of real conditions and load cycles [1].

The most critical emissions from diesel engines are nitrogen oxide and particle matter emissions, because they have harmful effects on human health. Both nitrogen oxide and particle emission are limited by regulations, the limiting values of which have been lowered over time (being now over 20 times lower than in the mid1990s.

Diesel engine produces nitrogen oxide and particle emissions, and the amount varies greatly on engine operation point and engine emissions are reduced by precise control of combustion process and exhaust after-treatment systems. Nitrogen oxides are reduced by exhaust gas recirculation and separate systems like the diesel oxidation catalyst, selective catalyst reduction or NOx storage catalyst, which are part of exhaust systems. Particle emissions are reduced by particulate filters. The size of these systems increases with the cleaning capacity. The size of the after-treatment systems is dependent on the emission reduction performance; if the raw emission can be reduced, the size of the aftertreatment systems can be smaller. 
Nitrogen oxide emissions and particle emissions are increased when engine load and/or speed is changing rapidly (compared to a constant load situation) [2]. Rapid and continuous changes of engine loading are typical for mobile machines such as excavator, forest harvesters, and wheel loaders. Secondly, the load and speed changes are dependent on the operator's behaviour. Previous studies by Heidari and Marr [3], Ericson, Westerberg, and Egnell [4], Lindgren [5], and Pult [6] have shown that NOx and particulate matter emissions factors are dependent on the engine transients.

The research question is: How much can raw emissions (i.e., emission before after-treatment systems) be reduced by different hydraulic hybrid concepts? To find an answer to the research question, the following experimental research was conducted. The use case was a log loading and unloading with the crane of forest forwarder. The reference system was a typical load-sensing (LS) system with variable pump and proportional valves. The comparison study was done with a hardware-in-the-loop system (HIL) that consisted of a real-time simulation model, hydraulic secondary controlled loading system, real diesel engine, and emission measurement systems. The studied systems were:

- The reference system with proportional valve and one load sensing pump;

- System with independent metering valves and electric load sensing system with one pump;

- Two parallel pumps with accumulator and independent metering valves;

- Accumulator with independent metering valves and on variable pump;

- So called STEAM system with one variable pump and two accumulators

- Four-pressure level system with one constant pump and accumulators

\section{STUDIED SYSTEMS}

The emission behavior of five different systems and one reference system were studied. The reference system consisted of crane hydraulics for a medium-sized forest forwarder that was used to collect and transport the logs. The maximum reach of the crane was $9.1 \mathrm{~m}$ and its lifting torque was about $95 \mathrm{kNm}$, while the slewing torque was $25 \mathrm{kNm}$. In addition, the slewing mechanics had a turning angle of 360 degrees. The hybrid systems were implemented in the crane hydraulics; the drive line was not hybridized and test cycle did not contain driving.

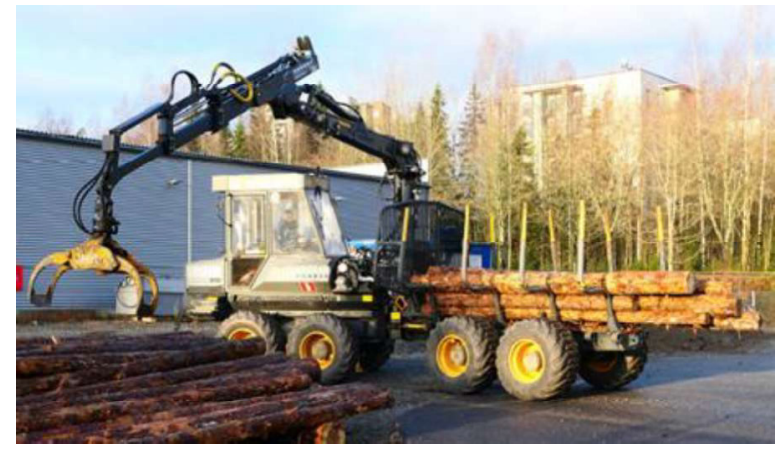

Figure 1: Studied reference forwared crane in action

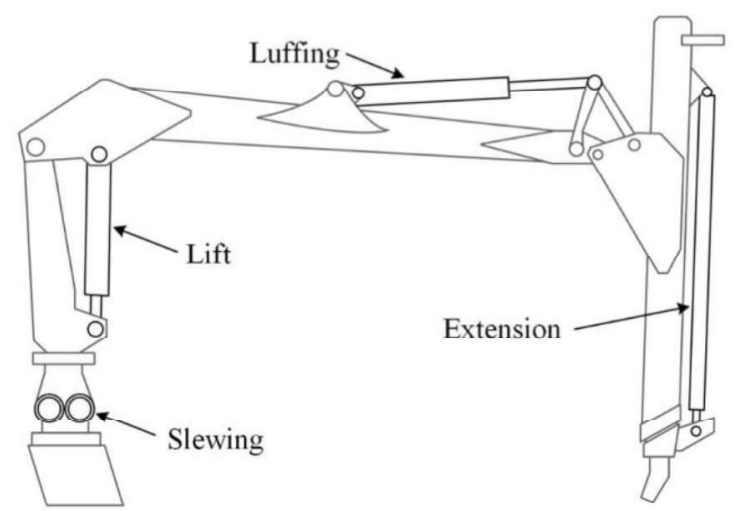

Figure 2: Studied crane of the forwarder

The reference system was a typical load-sensing system equipped with one pressure-controlled variable pump and load-sensing valve. The directional valve was controlled by electronic joysticks manipulated by an operator. The system contained slew, lift, luff, extension, and grapple actuators. The displacement of the pump was $130 \mathrm{~cm}^{3} / \mathrm{rev}$ and the maximum pressure was 27 MPa. The abbreviation LS-propo is used for the reference system.

In the first studied system, the original hydraulic load-sensing valve was replaced by an independent metering valves for all actuators and the load-sensing function was realized electronically (the abbreviation $L S-I M V$ is used for this). The pump displacement was $130 \mathrm{~cm}^{3} / \mathrm{rev}$ and the maximum pressure was $27 \mathrm{MPa}$. Figure 3 shows schematic realisation of the system (only one actuator showed). 


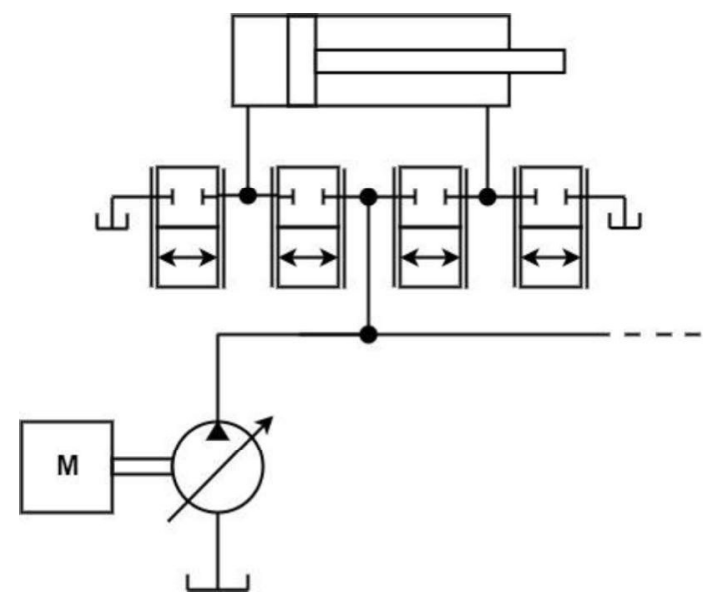

Figure 3: Simplified schematic of the $L S-I M V$ system

The second system had two pumps and the additional pump was parallel to the load-sensing pump. The additional pump was a closed-circuit pump and its second port was connected to an accumulator that enabled energy storing (Figure 4). References [7] and [8] introduce the system and its operation. This system also had independent metering valves. The system is abbreviated to Parallel pumps $+I M V$. The size of the open circuit pump was $50 \mathrm{~cm}^{3} / \mathrm{rev}$ and the size of the closed circuit pump was $60 \mathrm{~cm}^{3} / \mathrm{rev}$, with a maximum system pressure of $27 \mathrm{MPa}$. The nominal volume of the accumulator was 20 litres and the precharge pressure was $11.5 \mathrm{MPa}$.

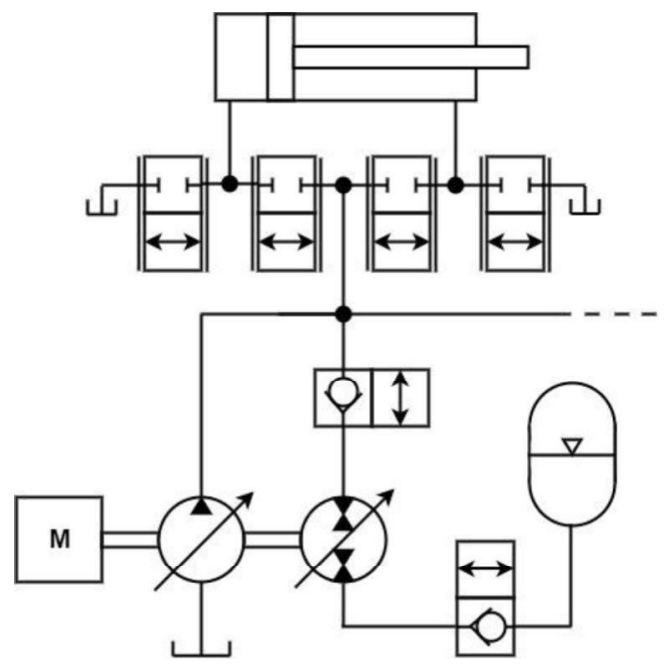

Figure 4: Simplified schematic of the Parallel pumps $+I M V$-system

The third system was similar to the LS-IMV system but had an accumulator as energy storage in the supply line. The connection (i.e., the flow in and out to the accumulator) was controlled by a valve with a variable opening. This system is abbreviated Throttled accu $+I M V$. Figure 5 shows a schematic realization of the system [9]. The pressure level was $27 \mathrm{MPa}$, the nominal size of the accumulator was 20 litres, and the precharge pressure was $11.5 \mathrm{MPa}$.

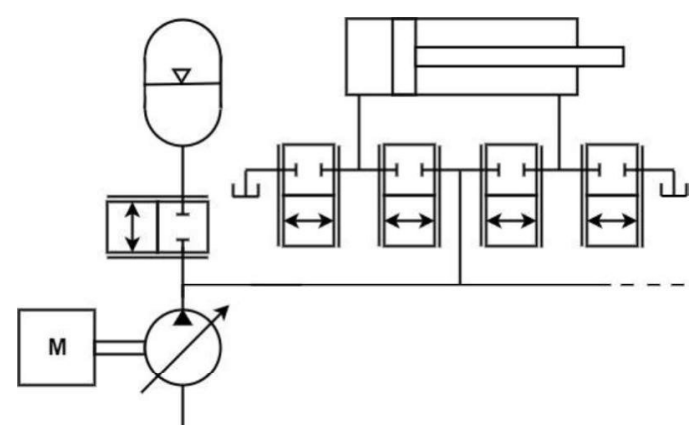

Figure 5: Simplified schematic of the Throttled $a c c u+I M V$-system

The fourth system was the so-called STEAM system which was invented and researched in RWTH Aachen [10]. It is a two-pressure system with low- and high-pressure supply lines with accumulators and is referred to as STEAM. Figure 6 shows a schematic realization of STEAM system. The pump for the STEAM-system was smaller $\left(25 \mathrm{~cm}^{3} / \mathrm{rev}\right)$ and the nominal volumes of the high- and low-pressure accumulators were both 15 litres and the precharge pressures $14 \mathrm{MPa}$ and $7 \mathrm{MPa}$ correspondingly. The maximum system pressure

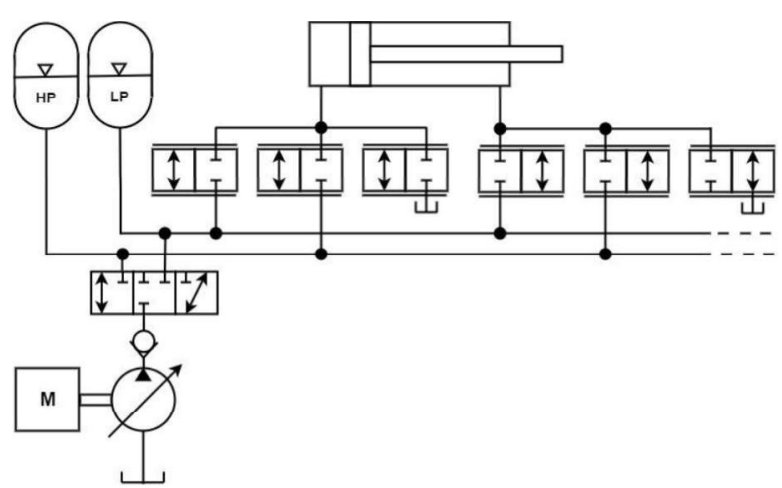

Figure 6: Simplified schematic of the STEAM-system was $28 \mathrm{MPa}$.

The last studied system was a multi-pressure system with four different pressure levels including return line pressure, called a Fourpressure system. Each pressure line had its own accumulator. Figure 7 shows a schematic realization of the Four-pressure system (a similar system is introduced by Huova et al [11]). The constant pump had a displacement of $20 \mathrm{~cm}^{3} / \mathrm{rev}$. The nominal volumes of all accumulators were 10 litres and the precharge pressures, from high 
to low, were 19.6 MPa, 13.1 MPa, 6.5 MPa respectively. The return line pressure was 0.1 $\mathrm{MPa}$. The maximum system pressure was 28

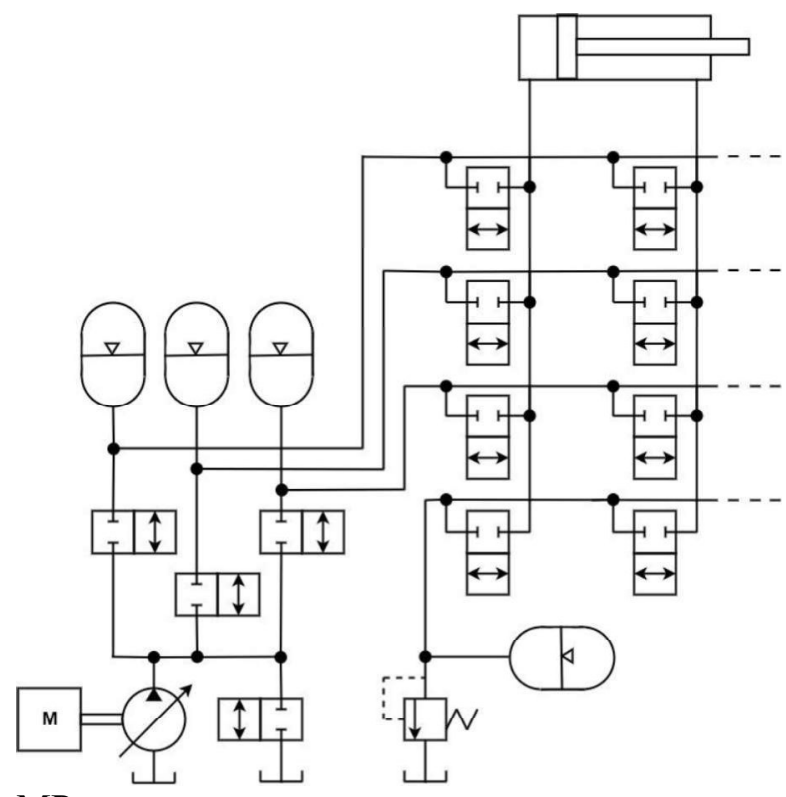

MPa.

Figure 7: Simplified schematic of the Four-pressuresystem

\section{MEASUREMENT SYSTEM}

The actual emissions of studied systems and reference were determined with the help of realtime simulation in combination a with real engine. The measurement system consisted of a diesel engine, loading unit that generated load to the engine and real-time control system. The load for the engine was determined by the simulation model of a particular hydraulic system. The inputs for the hydraulic system model were loading of the actuators. The load profiles of the actuators were real and they were measured from the reference crane of the forest forwarder. Emissions were measured by the $A V L$ 's PEMS system, which has measurement devices and systems for nitrogen oxides, carbon monoxide, carbon dioxide, hydrocarbons, soot, and particle mass. The post processing calculations of emission measurements were performed with AVL Concerto software. The measurements were performed in a laboratory at a temperature of about 20 degrees Celsius. The used fuel in the tests was regular diesel fuel. The system is shown in Figure 8.

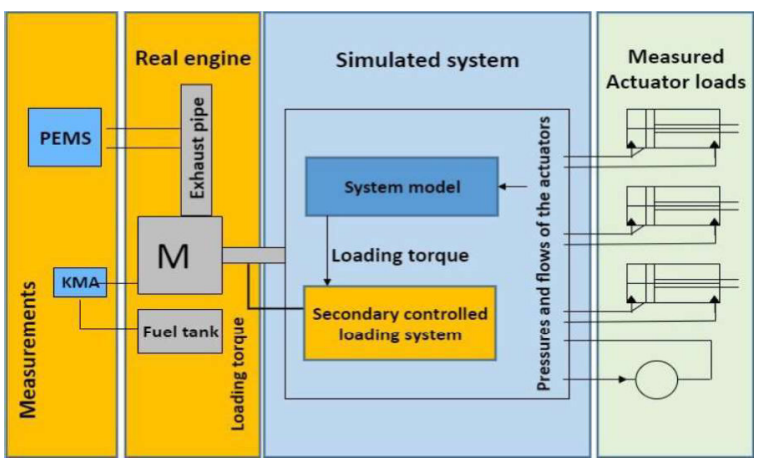

Figure 8: Measurement arrangement

\subsection{Load profiles}

The load profiles of crane actuators (i.e., slew drive, lift, luffing and extension) were captured during the reference measurements while loading and unloading logs with the crane of the forest forwarder. The power demands of grapple and its rotator were modelled as an average power, being $1 \mathrm{~kW}$. The reference cycle lasted around 20 minutes. The crane was operated during the reference cycle measurement by a professional operator. The torque generated by auxiliary cooling pump and driveline pumps (i.e., the boost pump and main pump) at zero displacement was modelled as a constant average and the torque demand was estimated to be $25 \mathrm{Nm}$.

\subsection{Simulation model}

All systems were modelled in Matlab/Simulink. The system models included actuators, main control valves, accumulators and pumps. The inputs for the system models were flows and pressures of the actuators which were captured during reference measurements. The backward simulation of the hydraulic system, including hybrid systems, was used to determine the pressures and flows of the hydraulic pump(s) and torque demand for the diesel engine. Calculations were based on steady-state models that was created based on the power loss models of the system components and control laws defining the use of valves and other subsystems. The analysis starts by calculation of input flow rate and required supply pressure level. A control law designed is used to select pump displacements, which fulfil these requirements. The analysis continues with the calculation of the mechanical input power of the pump. The power losses of the pumps are modelled as well as the pressure drop created by valves. The accumulator pressure level 
is modelled using an adiabatic model. Similar method is described in more detail in the reference [12]. The output of the system model is the torque demand for the diesel engine. The torque demand and engine speed set value were the used for set values for the HIL-system that was running in the dSpace DS1103-system.

\subsection{Loading unit}

A secondary controlled hydraulic system acted as a loading unit and generated the load torque for the diesel engine. The loading unit was capable of operating in four quadrants, but only one was utilized. The load system had the possibility for closed-loop torque or speed control, and in this case closed-loop torque control was used. The set torque was realised by controlling the swivel angle of two $125 \mathrm{~cm}^{3} / \mathrm{rev}$ axial piston units and the control loop was closed by a torque sensor between the engine and the loading unit. The maximum torque of the loading unit was $800 \mathrm{Nm}$. The rotational speed was controlled by the diesel engine and the set value was kept constant at either 1250,1400 , or $1600 \mathrm{rpm}$, respectively.

\section{RESULTS}

Table 1 shows the operational values of the studied system during the tests. Because of the decreased power demands of the hybrid systems, the engine speed was lowered from $1600 \mathrm{rpm}$ to $1250 \mathrm{rpm}$. The duration of all cycles was the same (20 minutes and 33 seconds) which means that absolute values are comparable between the systems.

The differences in torque and power demands are clearly seen from the mean torque and mean power values.

The efficiency results, shown in Table 2 , can be observed from different point of view. The cycle energy value indicates the energy need of the particular system and describes the efficiency of the hydraulic system because, in the all systems, the output work were equal. The Fourpressure system clearly had the lowest energy demand, requiring $49 \%$ less energy than the reference system for the same work. The secondbest system was the Throttled accu $+I M V$ system, requiring $43 \%$ less energy than the reference system. The third lowest energy need was found in the STEAM system, with a saving of about $38 \%$.
Table 1: Operational values

\begin{tabular}{lccc}
\hline & $\begin{array}{c}\text { Mean } \\
\text { engine } \\
\text { speed } \\
{[\mathbf{r p m}]}\end{array}$ & $\begin{array}{c}\text { Mean } \\
\text { engine } \\
\text { torque } \\
{[\mathbf{N m}]}\end{array}$ & $\begin{array}{c}\text { Mean } \\
\text { engine } \\
\text { power } \\
{[\mathbf{k W}]}\end{array}$ \\
\hline LS-propo & 1591 & 133 & 22.3 \\
LS-IMV & 1414 & 120 & 17.8 \\
Parallel & 1254 & 111 & 14.6 \\
pumps $+I M V$ & & & \\
Throttled & 1254 & 97 & 12.7 \\
accu + IMV & 1254 & 105 & 13.8 \\
STEAM & 1254 & 87 & 11.4 \\
Four pressure & & & \\
\hline
\end{tabular}

Table 2: Efficiency values, relative to the reference

\begin{tabular}{lccc}
\hline & $\begin{array}{c}\text { Cycle } \\
\text { energy }\end{array}$ & $\begin{array}{c}\text { Absolute } \\
\text { fuel } \\
\text { consum- } \\
\text { ption } \\
\text { [rel] }\end{array}$ & $\begin{array}{c}\text { Specific } \\
\text { fuel } \\
\text { consum- } \\
\text { ption } \\
\text { [rel] }\end{array}$ \\
\hline LS-propo & 1 & 1 & 1 \\
LS-IMV & 0.80 & 0.74 & 0.93 \\
Parallel & 0.66 & 0.64 & 0.97 \\
pumps + IMV & & & \\
Throttled & 0.57 & 0.60 & 1.06 \\
accu $+I M V$ & & & \\
STEAM & 0.62 & 0.67 & 1.09 \\
Four pressure & 0.51 & 0.60 & 1.17 \\
\hline
\end{tabular}

The absolute fuel consumption value indicates the energy needs of the whole system, including the hydraulic system and the diesel engine. Again, the Four pressure system had the lowest fuel consumption, with a decrease of $40 \%$ compared to the reference, but the difference between this and the second-best Throttled accu $+I M V$ system was only $0.6 \%$. The third-best system was the Parallel pumps + IMV system, which decreased the fuel consumption by $36 \%$. It is noteworthy that the differences between the systems were smaller in terms of fuel consumption than in terms of the energy needs of the hydraulic system. The reason for the diminishing differences between the systems, is that the low engine efficiency dominates the system efficiency and reduces differences across operation points.

The specific fuel consumption indicates the efficiency of the engine and it was calculated from the cycle energy (diesel engine shaft) and from the energy content of the used fuel. The lowest specific fuel consumption (i.e., the highest engine efficiency) occurred with the $L S-I M V$ system, which had 7\% lower specific 
consumption than the reference case. Interestingly, the most efficient hydraulic system (the Four-pressure system) caused the highest specific fuel consumption, with an increased specific consumption of $17 \%$ compared to the reference case. The reason for this phenomenon is that hybridization moves the engine operation point towards low torque and low speed region that have low efficiency. This fact illustrates very clear that hybridization requires a smaller engine to exploit all its benefits. The smaller engine would enable the engine to operate on favourable operation area in terms of efficiency resulting lower fuel consumption.

Figure 9 shows power demand of the studied systems for one log loading cycle. The full measurement contained about 20 loading and 20 unloading cycles. The total installed pump capacity is clearly seen on the steady state phase (145 - $146 \mathrm{sec})$, the system with smallest pumps (STEAM and Four pressure) have lowest power demand. The log loading phase (lifting, turning, lowering) is in the timeframe $147-160$ seconds and crane return phase respectively in the time frame $161-172$ seconds. The reference system ( $L S$-propo) has the highest power demand and remarkably many power peaks during the cycle. The shape of the power curves for $L S-I M V$, Parallel pumps $+I M V$ and throttled accu are quite similar only the level vary. The power curves for
STEAM and Four pressure-systems are different. This is a result of different operation principle on hydraulic power generation. In the both systems the pump flow is decoupled from the flow demand of the crane motion. The pressure of accumulators i.e state of charge of the accumulators controls the pump flow. This feature stabilizes the engine power demand and should reduce emissions as well.

As was mentioned, the engine did not have any exhaust after treatment systems. Therefore, the followed analysis is based on the raw emissions (i.e., emissions that are not processed by any catalysts or filters, such as a diesel oxidation catalyst, selective catalyst reduction, or particle filter). By decreasing the raw emissions it is possible to use smaller catalysts and filters, because decreased raw emissions reduces the required cleaning capacity of catalyst and filters.

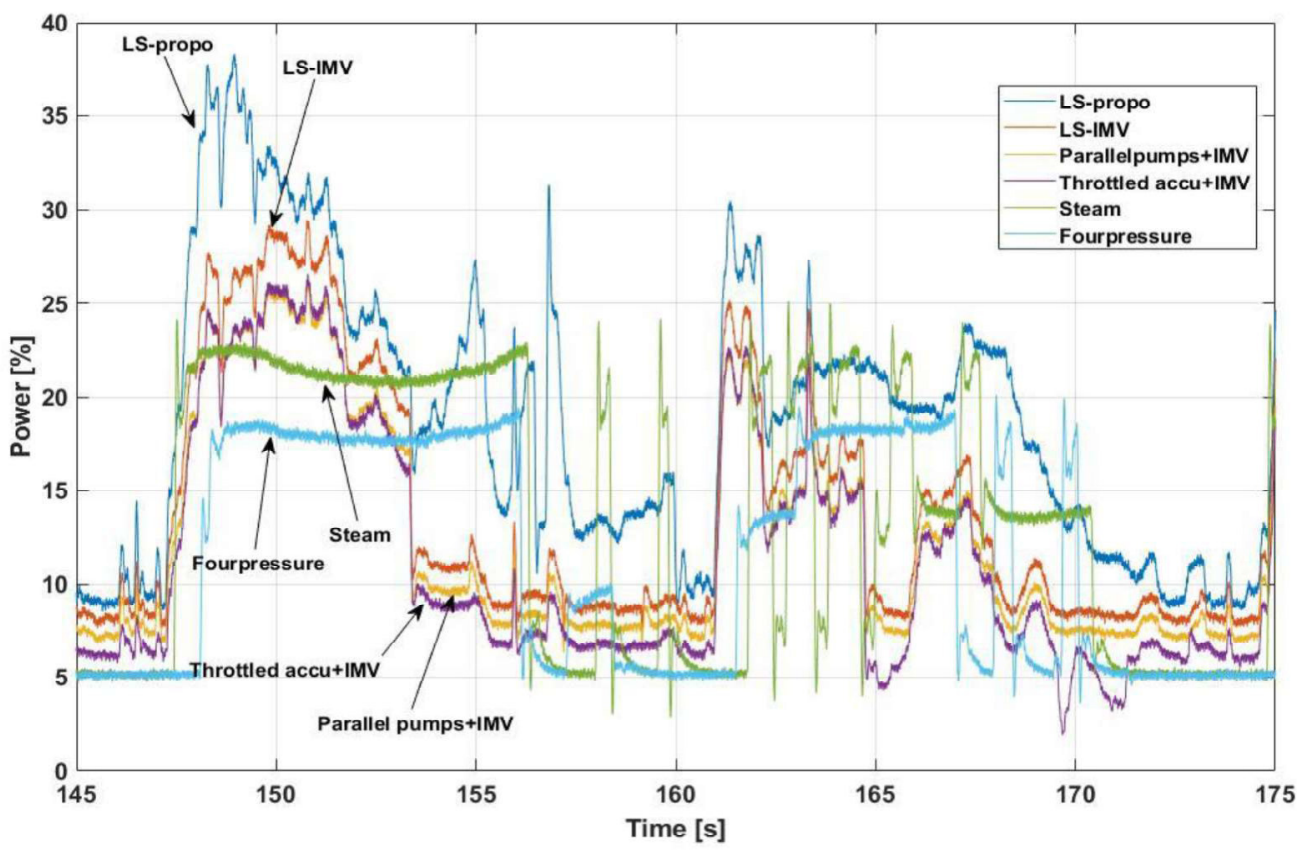

Figure 9: Sample of the engine power for one loading cycle 


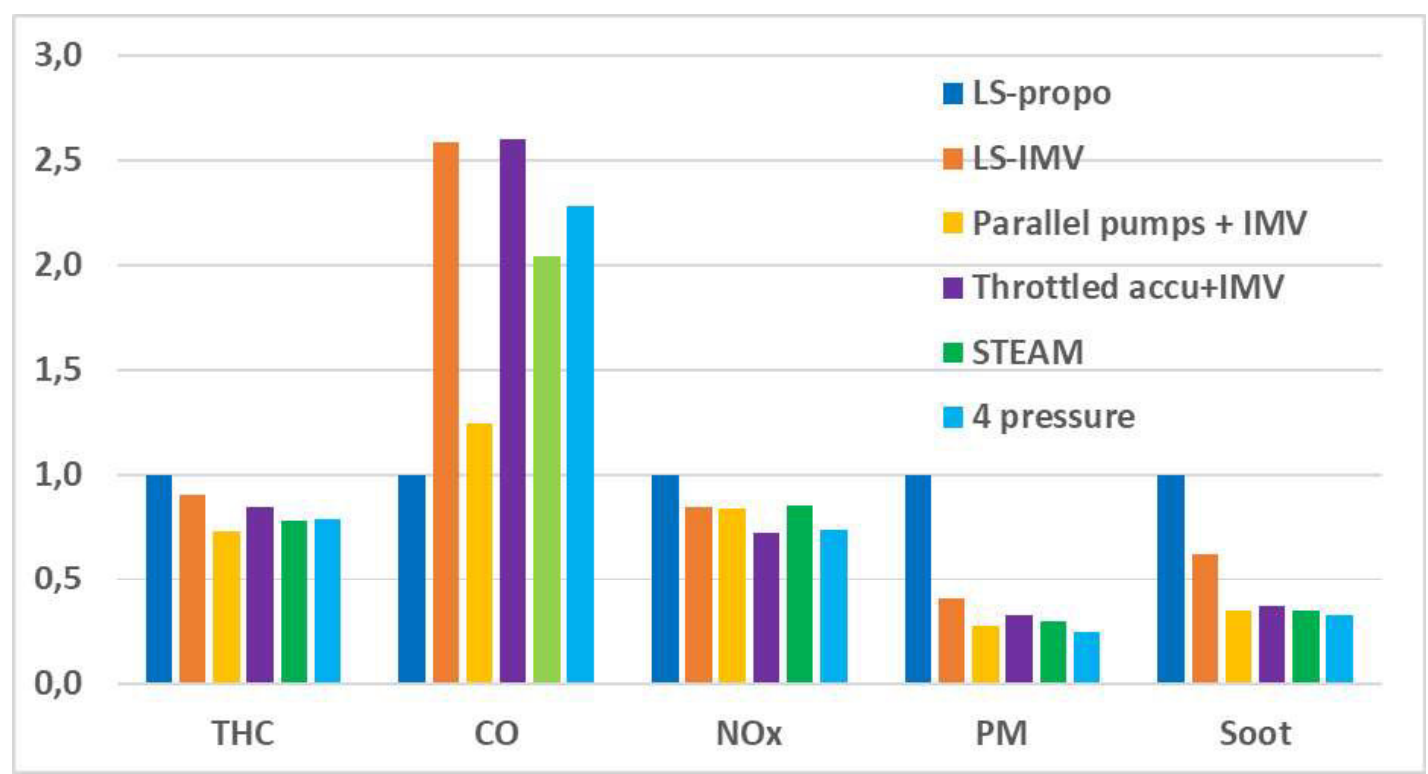

Figure 10: Relative change of absolute emissions; emissions of the LS-Propo system as reference. THC - Total hydrocarbons, CO — Carbon dioxide, NOx - Nitrogen oxide, PM - Particulate matter

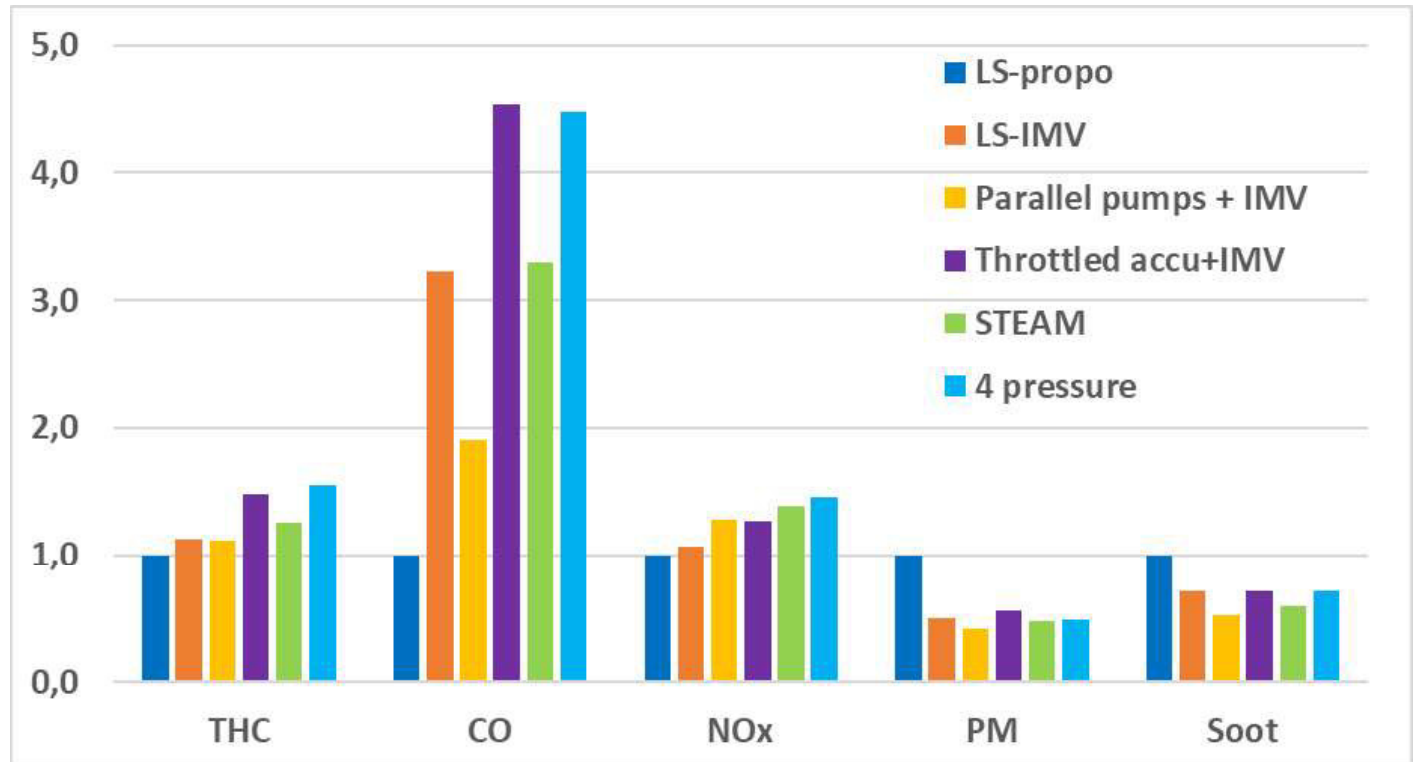

Figure 11: Relative change of specific emissions; emissions of the LS-Propo system as reference. THC - Total hydrocarbons, $\mathrm{CO}$ - Carbon monoxide, $\mathrm{NOx}$ - Nitrogen oxides, $\mathrm{PM}$ - Particulate matter

As an initial assumption, we theorized that emissions should decrease with fuel consumption. In real life, the load dynamics and changes in the engine operation points caused deviation from this assumption. The relative change of the absolute emissions are shown in Figure 10. Results show that absolute emissions can be reduced by hybridization. Nitrogen oxide emissions were $15-25 \%$ lower and particulate matter emissions were $60-75 \%$ lower. Overall, the Four-pressure system had the lowest emissions.
The exceptions to the above were carbon monoxide emissions, which showed an increase. The obvious reason for this is the operation points of the engine when hybrid systems are implemented. The new operation points are located in the low load area, load less than $30 \%$ of maximum at relative low engine speed. These together mean that the combustion and fuel-air mixture are not perfect. Therefore, in some local points in the combustion chamber, the fuel-air mixture is too rich and combustion lacks oxygen, creating carbon monoxide. For the same reason, 
the decrease of hydrocarbons is less than the decrease in fuel consumption because of incomplete combustion resulting in unburned hydrocarbons.

Nitrogen oxide emissions decreased through hybridization but not as much as expected. The reduction was less than the reduction in fuel consumption. Again, the reason for this is the unfavourable engine operation point from an emission formation point of view. The incomplete mixing of fuel and air resulted in very high local combustion temperatures, creating nitrogen oxide.

In terms of particulate matter emissions, the reduction was greater than the reduction in fuel consumption. This is caused by load profile and corresponds the hypothesis that reduction in load changes decreases particulate emission. In the hybrid systems, the load peaks are lower and fewer, which together has a reducing effect on particulate matter emissions and soot. It is known from earlier studies that rapid load changes induce particulate emissions and nitrogen oxide emissions.[2], [4].

The emission limits are defined in the legislation as specific emissions and Figure 11 shows the results as specific emissions i.e. the emissions are shown in terms of grams per delivered $\mathrm{kWh}$ at the engine shaft. Results differed compared to absolute values, and both specific hydrocarbon and specific nitrogen oxide emissions increased when hybridization was applied. This was caused by a non-optimal engine operation point resulting in an incomplete mixture formation and inefficient combustion from an emissions point of view. In contrast to this, specific particulate matter emissions decreased.

It can be deduced that the engine was not optimal sized for this use, because the specific emissions increased through hybridization. Smaller engine, which would operate at a more favourable operating point, would reduce fuel consumption and specific emissions.

The engine did not have any exhaust aftertreatment systems and therefore it was expected that the legislation limits (Stage 5, [1]) would not be met. The raw hydrocarbon and particulate matter emission were about 3-4 times higher than the legislation limits, and nitrogen oxide emissions were almost 20 times the limit value. However, the carbon monoxide emissions were only about $10-25 \%$ of the limit value.

\section{DISCUSSION}

The study was made without any exhaust aftertreatment system and the argument for this choice is: The aftertreatment system would reduce the difference between the studied system, obviously making the differences negligible. The changes in raw emissions give more information on the studied systems and their potential.

The backward simulation method was chosen because it allowed to make the comparison without extensive tuning of control algorithms for each system. Secondly, it made possible that all system made exactly same output work. The drawback of the backward method is that oscillations caused by system dynamics are not taken into account.

The independent metering system is not hybrid system but it was taken with because all studied hybrid systems utilize independent metering principle. This enables to determine the effect of hybridization apart from the independent metering in energy demand of the hydraulic system. The independent metering resulted about $20 \%$ reduction in energy need.

Interestingly, the most simplest hybrid system had the second lowest energy need. This is result of electronic load sensing which enables efficient accumulator charging and flow delivery to the actuators.

According the study hybrid systems reduce both fuel consumption and emissions and this study gives one view on this case. The full potential of fuel consumption and especially emission reduction remains unanswered. The main reason to this is engine sizing issue. After hybridization the engine was too big. This very clearly seen from the engine operation points, they located well below $50 \%$ of maximum power. However, the engine sizing issue is challenging in applications where the engine supplies many systems with different load demand. In a typical mobile machine the engine serves many systems such as the driveline, crane, and steering. Typically, the maximum power requirement of the driveline and the crane are at same level. Hybrid system with smaller engine and moderate energy storage capacity can fully serve the crane function but the driveline is different because the need of the maximum power lasts longer in time. This would require much bigger energy storage capacity even too big realized by hydraulic acumulator. So, the engine cannot be chosen 
according to crane use but according to driveline resulting big engine. From this point of view the results of this study are relevant.

Generalization of the results is always a worth of discussion when a such emission study is made using one application and one engine. The results show the same phenomenon as is observed in the earlier studies; minimizing variations in engine power results reduced emissions. From this point of view, results can be generalized. The absolute values of emission reduction are not applicable directly to other applications, because load profiles vary from one application to other. Also, different engine would give different absolute emission. The hypothesis; the size of the exhaust aftertreatment systems can be reduced by hybridization, cannot be fully guaranteed with these results, the emission reduction is too small. However the STEAM and Four-pressure systems have highest reduction potential because they decouple pump power demand from actuator power variation and enable engine load stabilization. From cost point of view the Throttled accumulator system has low investment costs compared to its benefits. To realize the full emission reduction potential of the hybridization the engine needs to be replaced by smaller one.

\section{CONCLUSION}

The most efficient system (i.e., the system with the lowest fuel consumption) was the Fourpressure system. However, the difference between this system and the Throttled accu + $I M V$ system was negligible, and fuel consumption for both was about $40 \%$ less than the reference system (LS-IMV system).

The initial assumption was that emissions would decrease with fuel consumption. In real life, the load dynamics and changes in the engine operation points caused deviation from this assumption. Overall, the results showed that absolute emissions can be reduced by hybridization. Nitrogen oxide emissions were $15-25 \%$ lower and particulate matter emissions were $60-75 \%$ lower, with the Four-pressure system having the lowest emissions.

Hybridization decreased nitrogen oxide emissions, but not as much as was expected (i.e., the reduction was less than the reduction in fuel consumption). The reason for this was the unfavourable engine operation point from an emission formation point of view. In terms of particulate matter emissions, the reduction was greater than reduction in the fuel consumption. In the hybrid systems the load peaks were lower and fewer, which had a reducing effect on particulate matter emissions.

As conclusion, it can be stated that all studied hybrid systems reduced remarkably fuel consumption and harmful emissions in the studied use case. The means that the emissions of the diesel engine powered mobile machines can be reduced by hydraulic hybrids.

\section{ACKNOWLEDGEMENTS}

At the time of the study all authors were employed by Tampere University of Technology. This study was funded by Business Finland.

\section{NOMENCLATURE}

$\begin{array}{ll}A V L & \text { AVL List GmbH } \\ C O & \text { Carbon monoxide } \\ C O 2 & \text { Carbon dioxide } \\ H C & \text { Hydrocarbon } \\ H I L & \text { Hardware in Loop } \\ I M V & \text { Independent metering valve } \\ L S & \text { Load Sensing } \\ N O x & \text { Nitrogen oxides } \\ P E M S & \text { Portable Emission Measurement System } \\ P M & \text { Particulate matter } \\ R W T H & \text { Rheinisch-Westfälische Technische Hochschule } \\ T H C & \text { Total Hydrocarbons } \\ g & \text { Gram } \\ k N m & \text { Kilonewton meter } \\ k W h & \text { Kilowatt hour } \\ M P a & \text { Megapascal }\end{array}$

\section{REFERENCES}

[1] EU. 2016. Regulation (EU) 2016/1628, 14.9.2016. On requirements relating to gaseous and particulate pollutant emission limits and type-approval for internal combustion engines for non-road mobile machinery, amending Regulations (EU) No 1024/2012 and (EU) No 167/2013, and amending and repealing Directive 97/68/EC

[2] Hagena, J.R, Filipi, Z.S., and Assanis D.N. (2006) Transient Diesel Emissions: Analysis of Engine Operation during a Tip-In. SAE Paper 2006-01-1151. 2006 SAE World Congress, Detroit (3-6 April 2006).

[3] Heidari, B. and Marr, L. C. (2015) Real-time emissions from construction equipment 
compared with model predictions. Journal of the Air \& Waste management Association. Vol. 62, No. 2, 115-125. DOI: 10.1080 $/ 10962247.2014 .978485$

[4] Ericson, C., Westerberg, B., and Egnell R. (2005) Transient Emission Predictions with Quasi-Stationary Models. SAE Paper 200501-3852. Powertrain Fluid Systems Conference and Exhibition, San Antonio, Texas (24-27 October 2005

[5] Lindgren, M. (2004) Engine Exhaust Gas Emissions from Non-road Mobile Machinery. Dissertation, Uppsala University, Acta Universitatis Agriculturae Suecia, Agraria 481. ISBN 91-576-6753-5

[6] Pult, F. and Geimer, M. (2019) Phlegmatization of a combustion engine for reduction of transient emissions. $16^{\text {th }}$ Scandinavian International Conference on Fluid Power, Tampere, Finland (22-24 May 2019).

[7] Einola, K. and Kivi, A. (2015) First experimental results of a hydraulic hybrid concept system for a cut-to length forest harvester. The Fourteenth Scandinavian International Conference on Fluid Power, Tampere, Finland (20-22 May 2015), 13 p.

[8] Erkkilä, M., Bauer, F., and Feld, D. (2013) Universal energy storage and recovery system - a novel approach for hydraulic hybrid. 13th
Scandinavian International Conference on Fluid Power, Linköping, Sweden (3-5 June 2013), $8 \mathrm{p}$

[9] Linjama, M., Huova, M., Tammisto, J., Heikkilä, M., Tikkanen, S., Kajaste, J., Paloniitty, M., and Pietola, M. (2019) Hydraulic hybrid working machines project Lessons learned. $16^{\text {th }}$ Scandinavian International Conference on Fluid Power, Tampere, Finland (22-24 May 2019).

[10] Vukovic, M., Leifeld, R., and Murrenhoff, H. (2016) STEAM - a hydraulic hybrid architecture for excavators. 10th International Fluid Power Conference, Dresden, Germany (8-10 March 2016), 151-162 (Vol. 3).

[11] Huova, M., Aalto, A., Linjama, M. Huhtala, K., Lantela, T., and Pietola, M. (2017) Digital hydraulic multipressure actuator - the concept, simulation study and first experimental results. International Journal of Fluid Power, Vol. 18, No. $3, \quad 141-152$. DOI: http://dx.doi.org/10.1080/14399776.2017.130 $\underline{2775}$

[12] Huova, M., Tammisto, J., Linjama, M., and Tervonen, J. (2018) Fuel efficiency analysis of selected hydraulic hybrids in a wheel loader application. BATH/ASME 2018 Symposium on Fluid Power and Motion Control, University of Bath, UK (12-14 September 2018). 